\title{
Sand smelt ability to cope and recover from ocean's elevated $\mathrm{CO}_{2}$ levels
}

\author{
Cátia S.E. Silva ${ }^{\mathrm{a}, *}$, Marco F.L. Lemos ${ }^{\mathrm{a}}$, Ana M. Faria ${ }^{\mathrm{b}}$, Ana F. Lopes ${ }^{\mathrm{b}}$, Susana Mendes ${ }^{\mathrm{a}}$, \\ Emanuel J. Gonçalves ${ }^{\mathrm{b}}$, Sara C. Novais ${ }^{\mathrm{a}, \mathrm{c}}$ \\ ${ }^{a}$ MARE - Marine and Environmental Sciences Centre, ESTM, Instituto Politécnico de Leiria, Avenida do Porto de Pesca, 2520-630 Peniche, Portugal \\ ${ }^{\mathrm{b}}$ MARE - Marine and Environmental Sciences Centre, ISPA - IU, Rua Jardim do Tabaco, 1149-041 Lisboa, Portugal \\ ${ }^{\mathrm{c}}$ Department of Ecological Science, Vrije University, Amsterdam, The Netherlands
}

\section{A R T I C L E I N F O}

\section{Keywords:}

Atherina presbyter

Biomarkers

Development

Lateralization

Ocean acidification

Hypercapnia

\begin{abstract}
A B S T R A C T
Considered a major environmental concern, ocean acidification has induced a recent research boost into effects on marine biodiversity and possible ecological, physiological, and behavioural impacts. Although the majority of literature indicate negative effects of future acidification scenarios, most studies are conducted for just a few days or weeks, which may be insufficient to detect the capacity of an organism to adjust to environmental changes through phenotypic plasticity. Here, the effects and the capacity of sand smelt larvae Atherina presbyter to cope and recover (through a treatment combination strategy) from short (15 days) and long-term exposure (45 days) to increasing $p \mathrm{CO}_{2}$ levels (control: $\sim 515 \mu \mathrm{atm}, \mathrm{pH}=8.07$; medium: $\sim 940 \mu \mathrm{atm}, \mathrm{pH}=7.84$; high: $\sim 1500 \mu \mathrm{atm}, \mathrm{pH}=7.66$ ) were measured, addressing larval development traits, behavioural lateralization, and biochemical biomarkers related with oxidative stress and damage, and energy metabolism and reserves. Although behavioural lateralization was not affected by high $p \mathrm{CO}_{2}$ exposure, morphometric changes, energetic costs, and oxidative stress damage were impacted differently through different exposures periods. Generally, short-time exposures led to different responses to either medium or high $p \mathrm{CO}_{2}$ levels (e.g. development, cellular metabolism, or damage), while on the long-term the response patterns tend to become similar between them, with both acidification scenarios inducing DNA damage and tending to lower growth rates. Additionally, when organisms were transferred to lower acidified condition, they were not able to recover from the mentioned DNA damage impacts.

Overall, results suggest that exposure to future ocean acidification scenarios can induce sublethal effects on early life-stages of fish, but effects are dependent on duration of exposure, and are likely not reversible. Furthermore, to improve our understanding on species sensitivity and adaptation strategies, results reinforce the need to use multiple biological endpoints when assessing the effects of ocean acidification on marine organisms.
\end{abstract}

\section{Introduction}

The unprecedented amount of carbon dioxide being released by anthropogenic sources (Kerr, 2010) has surpassed the oceans' capacity to absorb it, leading to changes in its chemistry in a process known as ocean acidification. With current rates of $\mathrm{CO}_{2}$ emissions, $\mathrm{pH}$ is expected to drop 0.3-0.4 units until the end of this century, from 8.1 to 7.8 or 7.7 (IPCC, 2014). These ocean $\mathrm{pH}$ changes, which are occurring at an unprecedented rate compared with similar events in the geological past, pose serious threats to marine life, which evolved over millions of years in a stable $\mathrm{pH}$ environment (Kerr, 2010).

Initially focused on corals and other calcified organisms due to its carbonate dependence (Orr et al., 2005; Hoegh-Guldberg et al., 2007), research into the effects of elevated $\mathrm{CO}_{2}$ has spread to other non- calcified marine organisms, such as fish. Early life stages might be particularly vulnerable (Melzner et al., 2009) given that physiological regulation mechanisms are poorly developed (Brauner, 2008). The available scientific findings report detrimental effects on larval growth (e.g. Baumann et al., 2012; Chambers et al., 2014; Silva et al., 2016; Rato et al., 2017), metabolism (e.g. Pimentel et al., 2015; Silva et al., 2016), sensorial perception (e.g. Dixson et al., 2010; Castro et al., 2017; Chung et al., 2014), and behaviour (e.g. Devine et al., 2012; Lopes et al., 2016). Moreover, exposure to increased $\mathrm{CO}_{2}$ levels may contribute to divert energy towards internal balance mechanisms, with increased metabolic costs (Silva et al., 2016), resulting in less energy available for other important tasks. As a result, these trade-offs may have major implications for survival, recruitment, and ultimately affect population replenishment and sustainability (Stiasny et al., 2016; Le

\footnotetext{
* Corresponding author.

E-mail address: sofia.silva@ipleiria.pt (C.S.E. Silva).
} 
Quesne and Pinnegar, 2012). Despite these evidences, most studies to date, on fish, involve short-term exposure periods to elevated $\mathrm{pCO}_{2}$ (usually less than 3 weeks), which may be insufficient to capture species' ability to acclimate to the environmental changes through phenotypic plasticity.

In a previous work with larvae of sand smelt, Atherina presbyter - a temperate, commercial, pelagic fish species from the Atlantic Ocean coasts - evidence of increased size and an ineffective antioxidant response capacity of larvae exposed to elevated $p \mathrm{CO}_{2}$ levels $(\sim 1800 \mu \mathrm{atm}$, $\mathrm{pH}=7.64$ ) for 15-days was found, while larvae from intermediate $p \mathrm{CO}_{2}$ levels $(\sim 1000 \mu \mathrm{atm}, \mathrm{pH}=7.85)$ presented smaller sizes, associated to increased energetic metabolism and an active antioxidant response system (Silva et al., 2016). These results suggest a fight-back cellular response at intermediate $p \mathrm{CO}_{2}$ levels, but the consequences of a longer-term exposure period are still unclear - the increased energetic costs could either result in higher mortality, later on when energy depots lower the minimum needed for regular organism homeostasis, or fish could potentially acclimate to increased $p \mathrm{CO}_{2}$ levels. Here the consequences of a longer-term exposure period (45 days) of sand smelt larvae to increasing $p \mathrm{CO}_{2}$ levels (control: $\sim 515 \mu \mathrm{atm}, \mathrm{pH}=8.07$; medium: $\sim 940 \mu \mathrm{atm}, \mathrm{pH}=7.84$; high: $\sim 1500 \mu \mathrm{atm}, \mathrm{pH}=7.66$ ), at biochemical, developmental, and behavioural level are addressed. Behavioural lateralization was chosen as the behavioural endpoint as a previous work with sand smelt larvae reported changes in lateralization under elevated $p \mathrm{CO}_{2}$ levels (Lopes et al., 2016). As the early assessment of climate change effects at the community and ecosystem level is particularly difficult, measurements at lower levels of ecological relevance have been extensively used to detect, and possibly extrapolate changes occurring at individual level (Lemos et al., 2010; Pan et al., 2015; Schunter et al., 2016). Biochemical biomarkers, mainly related with energy metabolism and oxidative stress, have been widely used as efficient tools to detect and monitor environmental variations and fitness costs (Huggett et al., 1992; Tonn et al., 2016; Silva et al., 2016; Kamyab et al., 2017). The exposure to environmental stressors may induce the formation of free radicals, contributing to the cellular vulnerability of organisms through lipid peroxidation (LPO) and/or DNA damage (Aguilera and Rautenberger, 2010; Lesser, 2011). To maintain cellular integrity, a set of antioxidant enzymes, including catalase (CAT) and superoxide dismutase (SOD), prevent the formation and/or remove these reactive metabolites (Abele and Puntarulo, 2004), while isocitrate and lactate dehydrogenase are associated with shifts on energetic metabolism, from aerobic to anaerobic, respectively (Huggett et al., 1992).

Together with the biomarkers approach, lateralization was chosen to assess the biochemical and morphological impacts in Atherina presbyter larvae induced by exposure to high levels of $p \mathrm{CO}_{2}$, while gaining insight on the adaptation and recovery to ocean acidification, through a treatment combination strategy and extended exposure period.

\section{Materials and methods}

\subsection{Ethics statement}

The current study was performed under the guidelines of the Portuguese Veterinary Authority (DGV-Portugal, following FELASA category C recommendations) and the European directive 2010/63/UE for the protection of animals used for scientific purposes.

\section{2. $\mathrm{pCO}_{2}$ treatments}

Sand smelt were exposed to control $p \mathrm{CO}_{2}$ levels $(\mathrm{pH} 8.07, \sim 515$ $\mu$ atm), and two elevated $p \mathrm{CO}_{2}$ treatments: medium ( $\mathrm{pH} 7.84, \sim 940$ $\mu \mathrm{atm})$ and high ( $\mathrm{pH} 7.66, \sim 1500 \mu \mathrm{atm})$. Control treatment was selected based on previous $\mathrm{pH}$ measures at the sampling site ( $\mathrm{pH}$ 8.05-8.07); the medium treatment was chosen based on $p \mathrm{CO}_{2}$ levels reported in the coastal areas where larvae of this species occur, where concentrations up to $1170 \mu \mathrm{atm}$ have been reported under upwelling events (Cabeçadas and Oliveira, 2005); the highest $p \mathrm{CO}_{2}$ treatment was chosen as an extreme condition, which may be reached in upwelling systems if the worst IPCC scenarios are met by 2100 .

The experiments were performed with artificial seawater resulting from the mixing of filtered freshwater with a salt mixture (TropicMarin ${ }^{\circledast}$ ) and adjusted to a salinity of $34.5 \%$. Except for the control treatment, where $\mathrm{pH}$ was directly influenced by ambient air, the two $\mathrm{pCO}_{2}$ treatments were achieved by $\mathrm{CO}_{2}$ injection. $\mathrm{pH}$ in the two $\mathrm{pCO}_{2}$ treatments was regulated by a pH computer (Tunze Aquarientechnik, Germany) connected to a $\mathrm{pH}$ probe connected to a 200-L sump. The $\mathrm{pH}_{\mathrm{NBS}}$ (National Bureau of Standards Scale), in the three treatments, was daily cross-checked using a portable meter (SevenGo DuoPro, SG23), which was also used for daily measures of temperature and salinity. Due to diffusion pumps on each sump, oxygen levels were always kept above $90 \%$ saturation. Each sump was equipped with diverse filtration sets (ultraviolet, chemical, biological, and mechanical), and delivered a continuous supply of recirculated seawater into five 35-L aquariums at a flow-rate of $\sim 600 \mathrm{~mL} \mathrm{~min}^{-1}$. Aquariums were sealed on top with a clear glass lid to limit $\mathrm{CO}_{2}$ exchange with the atmosphere. Ammonia, nitrates, and nitrites were monitored weekly and kept below critical levels.

Total alkalinity (TA) was determined on a weekly basis, using automated Gran titrations, with certified reference material supplied by A. Dickson (Scripps Institutions of Oceanography, San Diego). $p \mathrm{CO}_{2}$ was calculated in $\mathrm{CO}_{2} \mathrm{SYS}$ (Pierrot et al., 2006) using in situ temperature, $\mathrm{TA}$, and $\mathrm{pH}$, the carbonic acid dissociation constants given by Millero et al. (2006) and the $\mathrm{CO}_{2}$ solubility coefficient of Weiss (1974) for each of the experimental treatments (Table 1).

\subsection{Test organisms and experimental design}

Sand smelt larvae were collected at the surface, in the very nearshore, at Portinho da Arrábida, Portugal ( $\left.38^{\circ} 28^{\prime} 48^{\prime \prime} \mathrm{N} \mid 8^{\circ} 58^{\prime} 59^{\prime \prime} \mathrm{W}\right)$, using a $1 \mathrm{~mm}$ mesh hand net. Larvae were immediately transported to the laboratory and allowed to recover from handling effects for 2 days in 35-L tanks with recirculating seawater. Except for the two-days recovery period, larvae were daily fed ad libitum with Artemia nauplii and maintained under controlled temperature and salinity, and a summer light cycle of $14 \mathrm{~h}$ light: $10 \mathrm{~h}$ dark. Individuals were then randomly assigned to a control (C), medium $(\mathrm{M})$, or high $(\mathrm{H}) \mathrm{pCO}_{2}$ treatment, and maintained in five replicate 35-L tanks, per treatment, throughout the experiment. Initial larval density was $12-15$ larvae per tank $(N=73$ in control treatment, $\mathrm{N}=70$ in mid $p \mathrm{CO}_{2}$ treatment, and $\mathrm{N}=72$ in high $p \mathrm{CO}_{2}$ treatment). After 30 days in treatment, larvae were either transferred between treatments or left in the original treatment for another 15 days, thus totalling 45 days in treatment (CC, $\mathrm{CM}, \mathrm{CH}$; MM, MC, MH; $\mathrm{HH}, \mathrm{HC}, \mathrm{HM})$. No mortality was observed during the experiment, in any of the treatments. Larvae were randomly sampled at 15,30 , and 45

Table 1

Mean ( \pm SD) seawater parameters in the experimental system.

\begin{tabular}{|c|c|c|c|c|c|}
\hline$p \mathrm{CO}_{2}$ condition & $\mathrm{pH}_{\mathrm{NBS}}$ & $\mathrm{T}\left({ }^{\circ} \mathrm{C}\right)$ & S (psu) & $\mathrm{TA}\left(\mu \mathrm{mol} \mathrm{kg}^{-1}\right)$ & $p \mathrm{CO}_{2}$ ( $\left.\mu \mathrm{atm}\right)$ \\
\hline Control & $8.07 \pm 0.03$ & $16.0 \pm 0.3$ & $34.7 \pm 0.6$ & $2253 \pm 5$ & $516 \pm 43$ \\
\hline Medium & $7.84 \pm 0.01$ & $16.4 \pm 0.3$ & $34.9 \pm 0.2$ & $2245 \pm 3$ & $943 \pm 29$ \\
\hline High & $7.66 \pm 0.02$ & $16.6 \pm 0.2$ & $34.6 \pm 0.8$ & $2247 \pm 5$ & $1504 \pm 71$ \\
\hline
\end{tabular}


days, for morphometric and biochemical purposes, and sampled at 30 and 45 days for behavioural lateralization tests. Placing larvae immediately in a high $p \mathrm{CO}_{2}$ treatment, instead of adjusting to a gradual $\mathrm{pH}$ decrease, represent a toxicity challenge to the organisms and might limit data interpretation due to the possibility of a fast acclimation response to the surrounding environment. However, almost all experiments conducted to assess ocean acidification are acute experiments (Browman, 2016), which makes the present data comparable to most literature. Moreover, a recent review based on short- and long-term experiments revealed little evidence of acclimation to acidification for several species (Nagelkerken and Connell, 2015).

\subsection{Behavioural lateralization}

A total of 90 larvae $-\mathrm{N}=12$ per $p \mathrm{CO}_{2}$ treatment at 30 days and $\mathrm{N}=6$ per $p \mathrm{CO}_{2}$ condition at 45 days - were tested for behavioural lateralization (Table SI - Supplementary material). The test was conducted using a double t-chamber, adapted from Jutfelt et al. (2013), and Domenici et al. (2012) protocol. Briefly, each larva were transferred to the chamber and after $2 \mathrm{~min}$ a plastic rod was used to induce the animal to swim forward, without touching, until a left or right turning decision was made. The total turnings, after ten consecutive trial tests for each larva, were registered by direct observation. The relative lateralization index $\left(\mathrm{L}_{\mathrm{R}}\right)$, at the population level, was calculated using the formula (Bisazza et al., 1998):

$\frac{\text { Turns to the right }- \text { Turns to the left }}{\text { Turns to the right }+ \text { Turns to the left }} \times 100$

A mean $L_{R}$ near zero indicates that a given sample of the population is neither left- nor right-biased in its turning tendency, while extreme values of \pm 100 indicate that fish turned right or left, respectively, on all 10 trials (Bisazza et al., 2000). The degree of lateralization at the individual level, irrespective of its left and right direction, was assessed at the individual level using the absolute lateralization index $\left(\mathrm{L}_{\mathrm{A}}\right)$ :

$\mathrm{L}_{\mathrm{A}}=\left|\mathrm{L}_{\mathrm{R}}\right|$

At the end of the experiment, fish were immediately placed on an ice-cold plastic keeper to slow down the metabolism, photographed under a dissecting stereo microscope for length measurements, using Image-J (v1.48; U. S. National Institutes of Health, Bethesda, Maryland), and frozen at $-80^{\circ} \mathrm{C}$ until further processing.

\subsection{Morphometric analysis}

As described in Silva et al. (2016), the following morphometric traits were measured for each larva, as an indication of development (Jones and McCormick, 2002): standard length (SL), total length (TL), dorsal height (DH), caudal peduncle (CP), eye diameter (ED), and head length (HL) (Table SI - supplementary material).

\subsection{Biomarker analysis}

A total of 162 organisms - 15 replicate individuals per treatment at 15 and 30 days $(\mathrm{C} / \mathrm{M} / \mathrm{H})$ and 8 replicate individuals per treatment at 45 days (CC, CM, CH; MM, MC, MH; HH, HC, HM), were weighed and homogenized by an electrical homogenizer, in a 1:30 proportion (m:v) of potassium-phosphate buffer $(0.1 \mathrm{M}, \mathrm{pH}$ 7.4). After being separated into different microtubes, the homogenate was kept at $-80^{\circ} \mathrm{C}$ until further analysis of: lipid peroxidation levels [LPO; in a 50:1 mixture with BHT (2.6-dieter-butyl-4-metylphenol) $4 \%$ in methanol to avoid tissue oxidation], DNA strand breaks quantification, and all the components of energy available (Ea), namely total protein, carbohydrate and lipid content, and also the activity of the electron transport system (ETS) as a measure of cellular respiration and energy consumption (Ec). To obtain the mitochondrial supernatant (MS) and the post-mitochondrial supernatant (PMS), the rest of the homogenate was separated into two microtubes that followed different centrifugations, respectively: 1) centrifuged for $5 \mathrm{~min}$ at $3000 \mathrm{~g}\left(4^{\circ} \mathrm{C}\right)$, separated and stored at $-80^{\circ} \mathrm{C}$ for posterior analysis of the activity of lactate dehydrogenase (LDH) and isocitrate dehydrogenase (IDH); 2) centrifuged for $20 \mathrm{~min}$ at $10,000 \mathrm{~g}$ $\left(4{ }^{\circ} \mathrm{C}\right.$ ), separated and stored at $-80^{\circ} \mathrm{C}$ for posterior analysis of the activity of catalase (CAT) and superoxide dismutase (SOD).

All parameters were analysed and determined in triplicates, with blanks (potassium-phosphate buffer 0.1 M, pH 7.4), using a Synergy H1 Hybrid Multi-Mode Microplate Reader (BioTek Instruments, Vermont, USA).

The protein concentration (PT) in MS and PMS fractions was determined following Bradford (1976) method, using bovine $\mathrm{\gamma}$-globulin (BGG, Sigma-Aldrich, USA) as standard. Absorbance was read at $600 \mathrm{~nm}$ and results were expressed in $\mathrm{mg}$ of protein $\mathrm{mL}^{-1}$.

\subsubsection{Oxidative stress biomarkers}

Following McCord and Fridovich (1969), SOD activity was estimated using microplate and adaptations of Lima et al. (2007). This procedure is based on the reaction of generated superoxide radicals with cytochrome $\mathrm{C}$, which reduction can be followed and measured spectrophotometrically at $550 \mathrm{~nm}$ for $10 \mathrm{~min}\left(25^{\circ} \mathrm{C}\right)$. The presence of SOD decreases the reduction rate of cytochrome $\mathrm{C}$, by competing for the superoxide radicals. Using a SOD standard of $1.5 \mathrm{U} \mathrm{mL}^{-1}$, the enzyme activity was expressed in $\mathrm{U}$ mg of protein ${ }^{-1}$, where $50 \%$ of cytochrome $\mathrm{C}$ reduction can be inhibited by $1 \mathrm{U}$ of SOD.

CAT activity was determined based on the consumption of hydrogen peroxide $\left(\mathrm{H}_{2} \mathrm{O}_{2}\right)$ as a substrate following Clairborne (1985). The substrate decrease was followed spectrophotometrically at $240 \mathrm{~nm}$ for $1 \mathrm{~min}\left(25^{\circ} \mathrm{C}\right)$, using a molar extinction coefficient of $40 \mathrm{M}^{-1} \mathrm{~cm}^{-1}$.

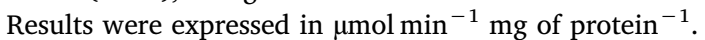

Following Ohkawa et al. (1979) and Bird and Draper (1984), the estimation of the content of thiobarbituric acid reactive substances (TBARS) allowed assessing LPO levels, quantified colorimetrically at $535 \mathrm{~nm}$ using a molar extinction coefficient of $1.56 \times 10^{5} \mathrm{M}^{-1} \mathrm{~cm}^{-1}$. Results were expressed in nmol TBARS $\mathrm{g} \mathrm{ww}^{-1}$.

DNA strand breaks analysis was based in the DNA alkaline precipitation assay (Olive, 1988) with adaptations from Lafontaine et al. (2000). The damaged DNA present in the supernatant links to Hoesch dye $\left(1 \mu \mathrm{gL}^{-1}\right.$ bis-benzimide, Sigma-Aldrich), allowing the estimation of damage levels by fluorescence, using an excitation/emission wavelength of $360 / 460 \mathrm{~nm}$. Calf thymus DNA was used to perform the standard curves and results were expressed as $\mu \mathrm{g}$ of DNA $\mathrm{mg} \mathrm{ww}^{-1}$.

\subsubsection{Energy metabolism related biomarkers}

The activity of LDH was measured following Vassault (1983) with adaptations of Diamantino et al. (2001). The process, based on the efficiency of LDH to convert pyruvate to lactate, allowed to detect a decrease in absorbance read at $340 \mathrm{~nm}$ for $5 \mathrm{~min}\left(25^{\circ} \mathrm{C}\right)$, as a result of NADH oxidation. A molar extinction coefficient of $6.3 \times 10^{3} \mathrm{M}^{-1} \mathrm{~cm}^{-1}$ was used, and results were expressed as nmol $\mathrm{min}^{-1} \mathrm{mg}$ protein ${ }^{-1}$.

The determination of IDH followed Ellis and Goldberg (1971) with the adaptations of Lima et al. (2007), was based in the decarboxylation of isocitrate by this enzyme. The increasing levels of NADPH, resulting from $\mathrm{NADP}^{+}$conversion, allowed the determination of IDH activity measured at $340 \mathrm{~nm}$ for $3 \mathrm{~min}\left(25^{\circ} \mathrm{C}\right)$. Results were expressed as nmol $\min ^{-1} \mathrm{mg}$ protein ${ }^{-1}$, with a molar extinction coefficient of $6.22 \times 10^{3} \mathrm{M}^{-1} \mathrm{~cm}^{-1}$.

Following De Coen and Janssen (1997, 2003), total content of protein, lipids and carbohydrates were measured as energy available (Ea) and expressed as $\mathrm{mJ}^{-1} \mathrm{mg} \mathrm{ww}^{-1}$. All energy reserves were determined and transformed into its energetic equivalent $\left(39.5 \mathrm{~kJ} \mathrm{~g}^{-1}\right.$ lipid, $24 \mathrm{~kJ} \mathrm{~g}^{-1}$ protein, $17.5 \mathrm{~kJ} \mathrm{~g}^{-1}$ glycogen) (Gnaiger, 1983). Energy consumption (Ec), given by the electron transport system (ETS) activity (King and Packard, 1975), was calculated by formazan generation, which caused an increase in absorbance at $490 \mathrm{~nm}$ for $3 \mathrm{~min}\left(25^{\circ} \mathrm{C}\right)$. Based on the stoichiometric relation that for every $2 \mathrm{mmol}$ of formazan 
formed $1 \mathrm{mmol}$ of $\mathrm{O}_{2}$ is consumed (De Coen and Janssen, 1997), the oxygen consumption rate was calculated and then transformed into caloric values using oxyenthalpic equivalents of $484 \mathrm{~kJ} \mathrm{~mol}^{-1} \mathrm{O}_{2}$ (Gnaiger, 1983). Results were expressed as $\mathrm{mJ} \mathrm{h}^{-1} \mathrm{mg} \mathrm{ww}^{-1}$.

\subsection{Data analysis}

The effect of $p \mathrm{CO}_{2}$ treatment (control, medium, and high) on behavioural lateralization and biochemical endpoints was addressed by one-way analysis of variance (ANOVA), followed by Tukey post-hoc test for multiple comparisons between treatments, within each timepoint (Zar, 2010). When normality and homoscedasticity were not validated, Kruskal-Wallis was applied (Zar, 2010) followed by Least Significant Difference or Games-Howell post-hoc test for multiple comparisons between treatments. Only the effects within each timepoint were considered given the different developmental stages of the larvae over time. The influence of $p \mathrm{CO}_{2}$ treatment (control, medium, and high) on morphometric traits was analysed using a multivariate analysis of variance (MANOVA). In addition, a Principal Component Analysis (PCA; Ter Braak, 1986) was performed to evaluate the pattern of distribution and correlation based on all endpoints (biomarkers, morphometry, and behaviour) and treatments. When applicable, data were standardized and $\log (\mathrm{x}+1)$ transformed (Legendre and Legendre, 1979). All univariate statistical tests were performed with IBM SPSS Statistics 23. PCA was performed with CANOCO version 4.5 package (Ter Braak and Smilauer, 1998). Results were presented as mean \pm standard-deviation (SD) and significance level was set at $\mathrm{P}<0.05$.

\section{Results}

\subsection{Lateralization}

Absolute and relative lateralization did not differ significantly among treatments at $30\left(\mathrm{~F}_{(2,33)}=2.882 ; \mathrm{P}=0.070\right.$, and $\mathrm{F}_{(2,33)}=0.939$; $\mathrm{P}=0.401$, respectively; Table SII - supplementary material) and 45 days of exposure $\left(\mathrm{F}_{(2,15)}=0.637 ; \mathrm{P}=0.542\right.$, and $\mathrm{F}_{(2,15)}=0.060$; $\mathrm{P}=0.942$, respectively; Table SII - supplementary material). Similarly, no differences in $\mathrm{L}_{\mathrm{A}}$ and $\mathrm{L}_{\mathrm{R}}$ were detectable when also considering the transference between treatments at 45 days (CC, CM, CH; MM, MC, MH; $\mathrm{HH}, \mathrm{HC}, \mathrm{HM}) \quad\left(\mathrm{F}_{(8,45)}=0.989 ; \mathrm{P}=0.457\right.$ and $\mathrm{F}_{(8,45)}=1.448$; $\mathrm{P}=0.203$, respectively).

\subsection{Morphometry}

The results obtained, and here depicted through a MANOVA analysis, show that none of the morphometric traits were affected by $\mathrm{pCO}_{2}$ treatment at any timepoint. The exception occurred only for HL, which was significantly different between medium and high $p \mathrm{CO}_{2}$ treatment at 15 days of exposure $\left(\mathrm{F}_{(2,42)}=7.802 ; \mathrm{P}=0.001\right.$; Table SII - supplementary material). Nonetheless, the PCA results for the 15 day of exposure demonstrated a trend for higher lengths in high $p \mathrm{CO}_{2}$ treatment (dark blue grouping) and smaller larvae in control and medium $p \mathrm{CO}_{2}$ treatments (light blue grouping), as well as a separation of responses between treatments (Fig. 1a). Thus, increasing $\mathrm{pCO}_{2}$ levels tends to increase mostly the morphometric traits ED, TL, SL, DH, and HL, also emphasizing the weaker correlation between HL and the remaining morphometric traits, which reinforces MANOVA results regarding acidification effects on this variable - lower $\mathrm{HL}$ in medium $p \mathrm{CO}_{2}$ treatment and higher HL in the highest treatment.

At 30 days of exposure, the treatment separation tendency was maintained, and all morphometric traits became more correlated and more positively associated with the high $p \mathrm{CO}_{2}$ treatment (Fig. 1b). After 45 days of continuum exposure to the same $\mathrm{pCO}_{2}$ conditions, although no significant differences were detected, and the treatment separation tendency was maintained, a reverse pattern was revealed for all morphometric traits, with exception of CP (Fig. 1c). CP remained highly related with high and medium $p \mathrm{CO}_{2}$ treatments, while the strong correlation of the remaining morphometric vectors was at this point more associated to control $p \mathrm{CO}_{2}$ treatment.

Considering the transfer between treatments (CC, CM, CH; MM, MC, $\mathrm{MH}$; HH, HC, HM), at 45 days no statistical significant differences were detected although the tendency for higher morphometry lengths under more acidified conditions, particularly $\mathrm{CP}$, SL, and ED, was observed once more (Fig. 1d).

\subsection{Biomarker analysis}

The biomarker analysis revealed different responses over time considering oxidative stress and energy metabolism related parameters (Fig. 2; Table SII; Fig. SI and SII- supplementary material).

At 15 days of exposure, enzymatic activities of IDH and LDH showed statistically significant differences, with higher activities detected in medium $p \mathrm{CO}_{2}$ treatment for IDH $\left(\mathrm{F}_{(2,42)}=49.941 ; \mathrm{P}=0.000\right.$; Table SIII and Fig. SI - supplementary material) as well as for LDH (Least Significant Difference; $\chi_{(2)}^{2}=283.376 ; \mathrm{P}=0.000$; Table SIII and Fig. SI supplementary material). Overall Ea also presented statistically significant differences $\left(\mathrm{F}_{(2,42)}=3.542 ; \mathrm{P}=0.038\right.$; Table SIII and Fig. SI supplementary material). This scenario was probably influenced by the LP content, which showed the same response pattern $\left(\mathrm{F}_{(2,42)}=4.749\right.$; $\mathrm{P}=0.014$; Table SII and Fig. SI - supplementary material), meaning higher values in the medium $p \mathrm{CO}_{2}$ treatment than in control both for LP (Tukey; P = 0.014; Table SIII and Fig. SI - supplementary material) and Ea (Tukey; P = 0.031; Table SIII and Fig. SI - supplementary material). Regarding oxidative stress parameters, no statistical differences were observed for any measured parameters at 15 days of exposure. The only exception occurred for LPO, where the levels under the high $p \mathrm{CO}_{2}$ treatment were significantly lower than in control (Least Significant Difference; $\chi_{(2)}^{2}=17.139 ; \mathrm{P}=0.030$; Table SIII and Fig. SII - supplementary material). These responses can be easily depicted from the PCA analysis (Fig. 1a), where a strong association between the previously mentioned parameters LDH, IDH, LP, and Ea, and the medium $p \mathrm{CO}_{2}$ treatment is observed (light blue grouping) and determinant to explain $71.6 \%$ of the total variance expressed. Apart from the increased morphometric traits already mentioned (Section 3.2), at this time point the high $p \mathrm{CO}_{2}$ treatment was also associated with higher Ec values and lower values of oxidative stress parameters, namely LPO, as seen by the opposite orientation of the LPO vector (Fig. 1a; dark blue grouping).

After 30 days of exposure, a reverse pattern was detected for LPO, with higher levels in high $p \mathrm{CO}_{2}$ treatment $\left(\mathrm{F}_{(2,42)}=5.588 ; \mathrm{P}=0.005\right.$; Table SIII and Fig. SII - supplementary material), while DNA damage levels decreased from control to high treatment (Tukey; $\mathrm{P}=0.022$; Table SIII and Fig. SII - supplementary material). Energy consumption levels were higher in organisms exposed to medium $\mathrm{pCO}_{2}$ treatment $\left(\mathrm{F}_{(2,42)}=5.249 ; \mathrm{P}=0.009\right.$; Table SIV and Fig. SI - supplementary material), and lower carbohydrates ( $\mathrm{CBH}$ ) levels were detected in larvae from high $\mathrm{pCO}_{2}$ treatment (Least Significant Difference; $\chi_{(2)}^{2}=61.658 ; \mathrm{P}=0.003$; Table SIII and Fig. SI - supplementary material), being this biomarker highly determinant to explain $65.7 \%$ of the total variance expressed in the PCA (Fig. 1b; dark blue grouping). Along with the decreased $\mathrm{CBH}$, and lower DNA damage levels, the high $p \mathrm{CO}_{2}$ treatment was found highly associated with increased morphometric traits, high LDH, SOD, and IDH activities, as well as with the before mentioned high LPO levels (Fig. 1b). The 30 days exposure to medium $p \mathrm{CO}_{2}$ treatment was characterized mainly by higher levels of PT and Ec, together with lower levels of LP (Fig. 1b; light blue grouping).

At the longest timepoint, the DNA damage tendency observed at 30 days was reverted at 45 days of exposure, with larvae presenting superior damage levels with both acidification treatments (Tukey; $\mathrm{P}=0.000$; Table SIII and Fig. SII - supplementary material). A reverse response pattern was also observed for Ec, where the oxygen consumption rates were higher in larvae from the high $p \mathrm{CO}_{2}$ treatment (dark blue grouping) when compared to the medium treatment (Tukey; 

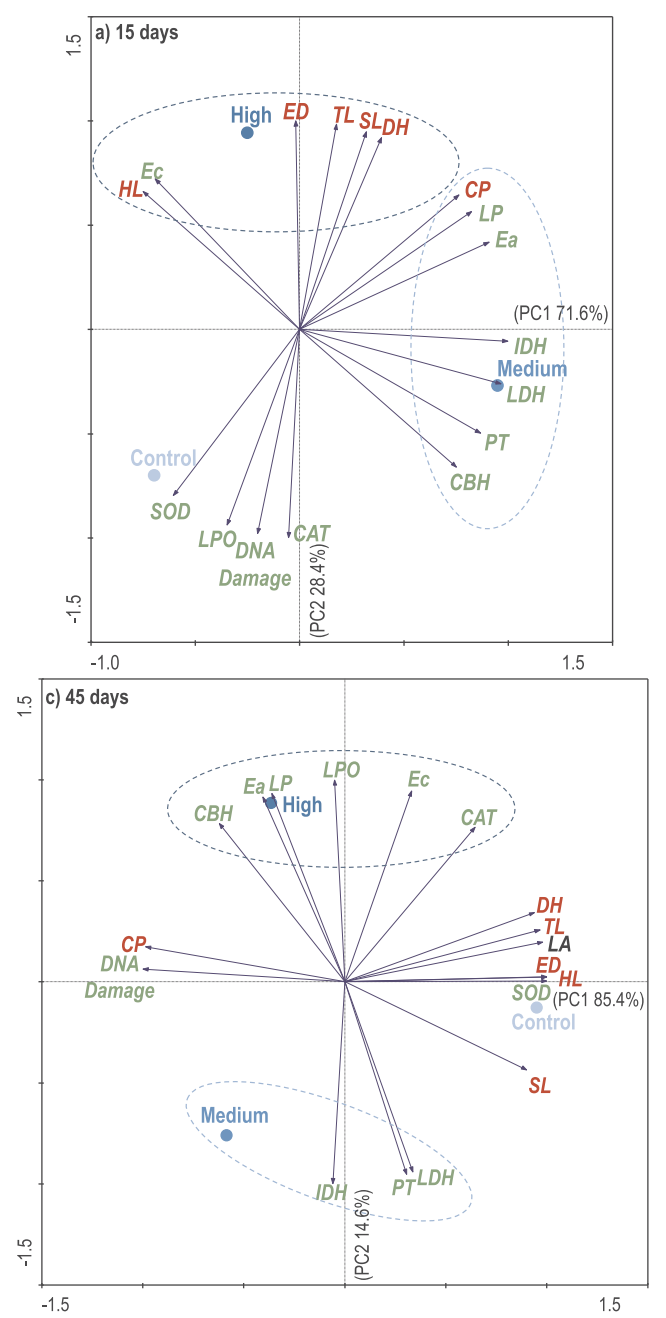
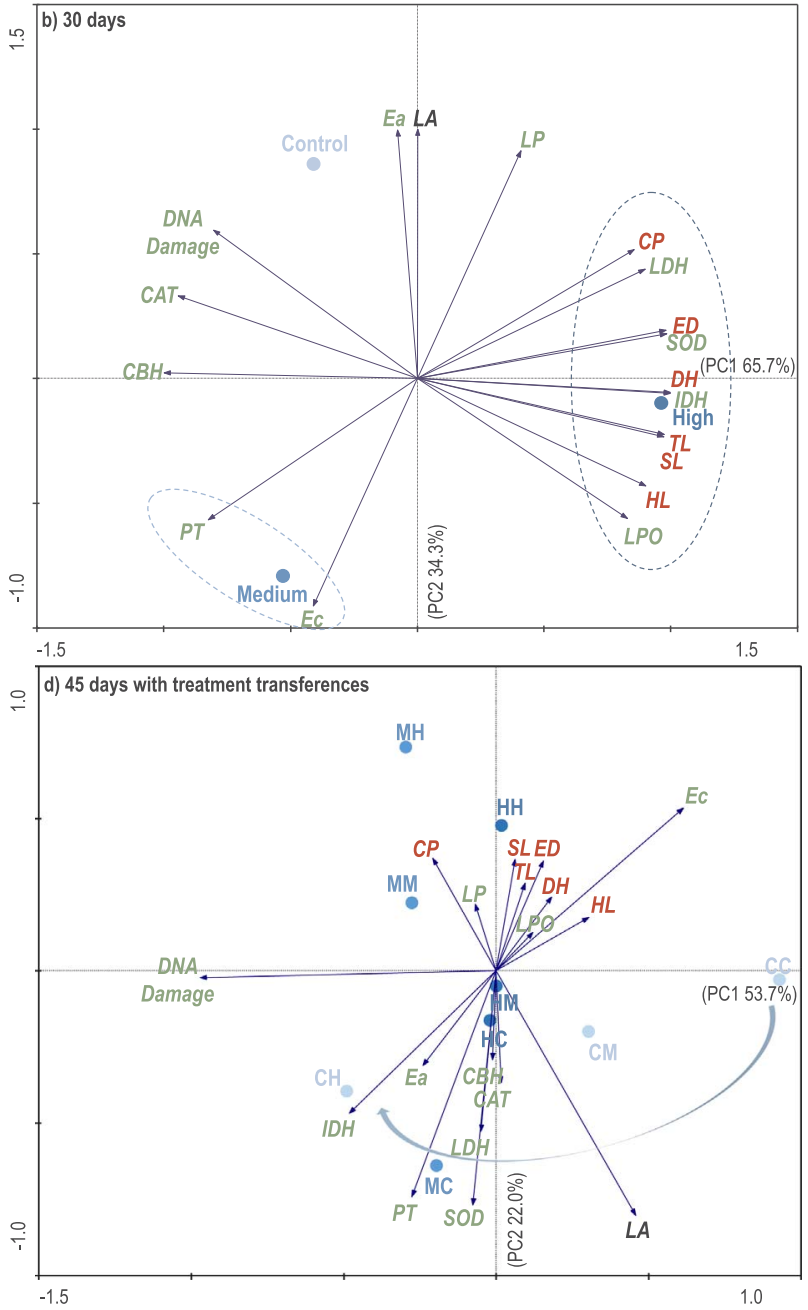

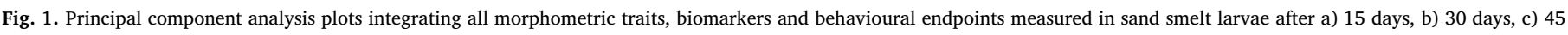

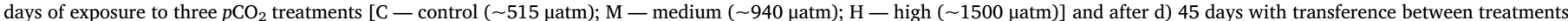

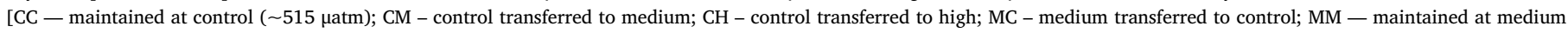

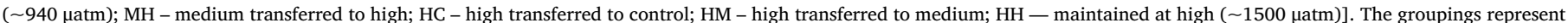

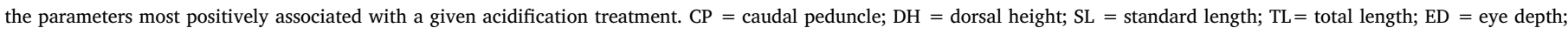

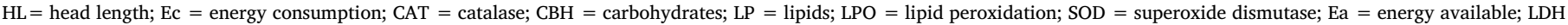

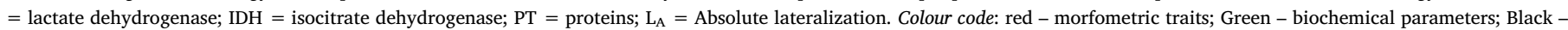
Behavioural parameter; Blue $-p \mathrm{CO}_{2}$ treatments. (For interpretation of the references to color in this figure legend, the reader is referred to the web version of this article).

$\mathrm{P}=0.004$; Table SIII and Fig. SI - supplementary material). The association between higher DNA damage under acidification conditions is also clear from the PCA analysis of 45 days (Fig. 1c), which together with higher $\mathrm{CP}$ values, and lower SOD, $\mathrm{L}_{\mathrm{A}}$ and most other morphometric traits, are characteristics of organisms under acidification treatments and determinant to explain $85.4 \%$ of the total variance expressed (Fig. 1c).

Regarding the 45 days after the treatment transference (CC, $\mathrm{CM}, \mathrm{CH}$; MM, MC, MH; HH, HC, HM), the parameters that most contributed to explain the variability of data were DNA damage, Ec, $\mathrm{L}_{\mathrm{A}}$, PT, and SOD (Fig. 1d), although only few significant differences were detected for the measured biomarkers, namely for Ec, SOD, and DNA damage (Fig. 2; Table SII and SIV - supplementary material). In particular the DNA damage endpoint highlights the apparent irreversibility of effects detected for organisms that had been previously exposed to either medium or high $p \mathrm{CO}_{2}$ treatments and then transferred to lower acidification conditions (same levels from MM to MC, and from HH to HC and HM; Fig. 1d and Fig. 2c). However, when organisms under control conditions were transferred to medium or high treatments for the same period of time, DNA damage levels increased abruptly (from CC to CM and CH; Fig. 1d and Fig. 2c), greatly contributing for the $53.7 \%$ of the PCA total variance (Fig. 1d). Interestingly, and contrary to the previous cases, here all the remaining vectors presented lower dimensions, being less relevant to contribute to the overall pattern.

\section{Discussion and Conclusion}

During the past decade, behaviour modification has been widely used as an indicator of ocean acidification stress, not only due to its inherent plasticity but also to its direct relation with physiological processes (Nagelkerken and Munday, 2016). Detrimental effects on fish have been related with neuronal functions impairment in acidosis scenarios (Hamilton et al., 2014), meaning that behavioural changes may reflect physiological impacts and compensatory mechanisms (Chivers et al., 2014; Heuer and Grosell, 2014). Studying responses to ocean acidification at different levels of biological organization, from enzymatic activities to behaviour and organism development, has been highlighting changes in energy allocation and dramatic compensations at cellular level, even in cases underlying an apparent resilience (Le Quesne and Pinnegar, 2012; Pan et al., 2015). Despite the importance 


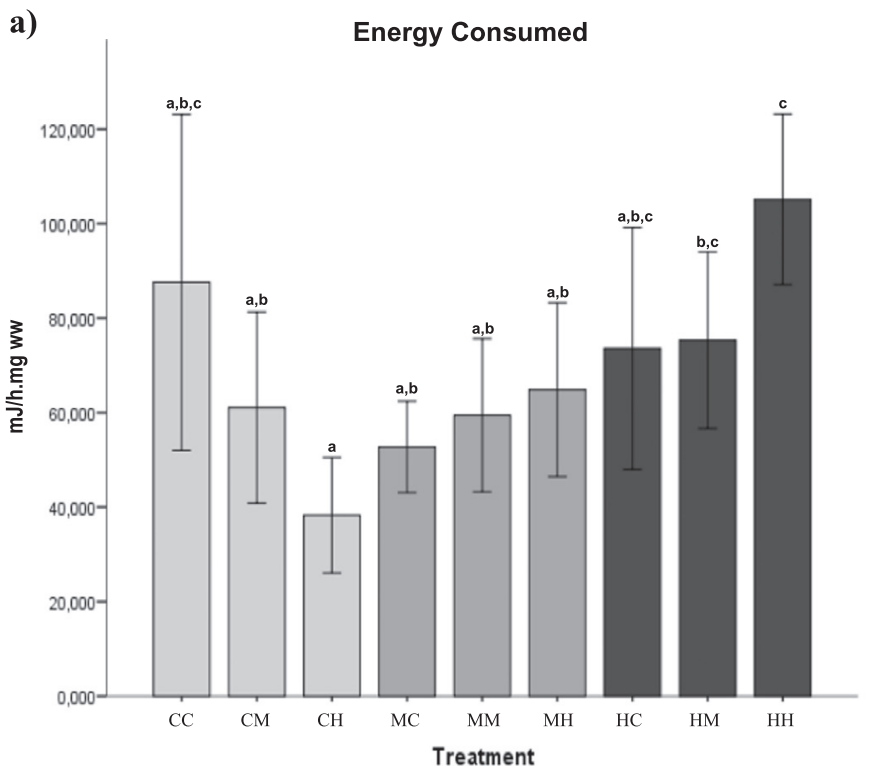

b)

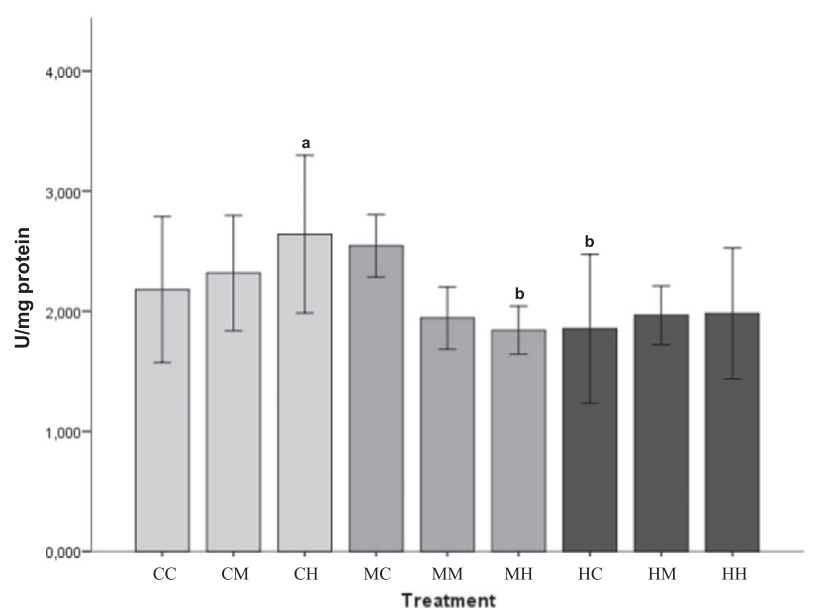

c)

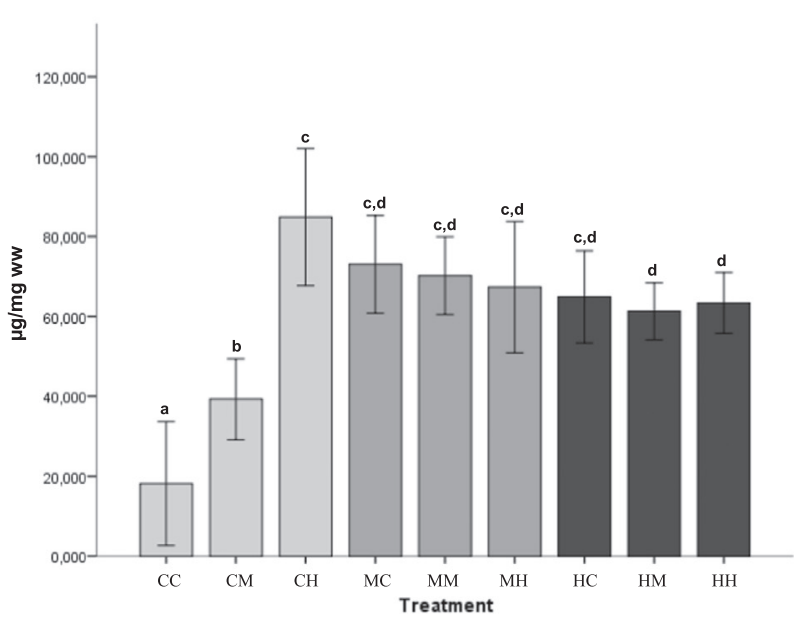

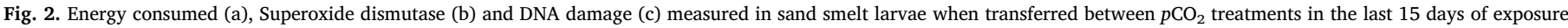

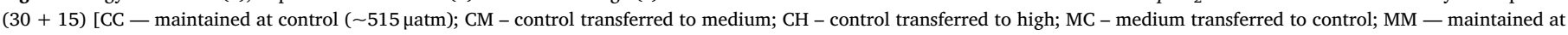

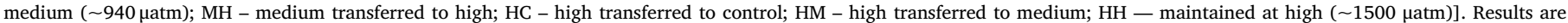
expressed as mean \pm SD. Different letters represent statistical significant differences (Games-Howell or Tukey, P $<0.05$ ).

of assessing species-by-species impacts and adaptation capacity to ocean acidification, little has been carried out to broaden and link these different areas, hampering our understanding on identifying processes and mechanisms subjected to selective pressures.

Lateralization has been reported as a sensitive behavioural endpoint in some organisms exposed to ocean acidification, which impact was already confirmed in Atherina presbyter larvae (Lopes et al., 2016), who reported decreased lateralization index after 7 and 21 days of exposure to high $p \mathrm{CO}_{2}$ levels $(\sim 2080 \mu \mathrm{atm}, \mathrm{pH}=7.61)$. However, in the present study, the difference was not statistically significant (Table SII). The different results might be attributed to differences in experimental designs - in the present study the highest $p \mathrm{CO}_{2}$ condition was still below the extreme $p \mathrm{CO}_{2}$ level used by Lopes et al. (2016) $(\sim 1500 \mu \mathrm{atm}$ vs. $\sim 2080 \mu \mathrm{atm}$ ), as well as the longer-exposure period of 30 and 45 days. Sand smelt larvae may have acclimated to the tested $p \mathrm{CO}_{2}$ conditions, and/or the highest tested $p \mathrm{CO}_{2}$ level was insufficient to induce changes at the lateralization level.

Considering previous results obtained by Silva et al. (2016), the general morphological analysis from this study revealed the same trend for larger sizes for larvae in high $\mathrm{pCO}_{2}$ conditions and smaller sizes for larvae in medium and/or control treatment, after 15 and 30 days of exposure (Fig. 1a and b, respectively). Corroborating this trend, a treatment effect was detected for HL between medium and high $p \mathrm{CO}_{2}$ treatment, after 15 days of exposure, revealing larger head lengths with increasing $p \mathrm{CO}_{2}$ condition (Fig. 1a). Despite the lack of statistically significant differences among treatments for the other morphometric traits, a reversible tendency was observed after 45 days of exposure to the same $\mathrm{pCO}_{2}$ levels (Fig. 1c). With the exception of $\mathrm{CP}$ - maintaining the same trend - all morphometric traits presented a tendency to increase in control conditions, with medium and high $\mathrm{pCO}_{2}$ treatments inducing an opposite effect. Although ocean acidification impacts are often species specific, reduced growth sizes associated with the exposure to high levels of $p \mathrm{CO}_{2}$ have been reported and related mainly with decreased energy levels available for tissue synthesis and other important functions, given that physiological adaptation mechanisms rely on expensive metabolic costs (Baumann et al., 2012; Hamilton et al., 2017). Other studies, on the contrary, have provided evidence of increased growth or a lack of effect under increased environmental $p \mathrm{CO}_{2}$ (Munday et al., 2009b, 2011; Hurst et al., 2012; Perry et al., 2015), which has been associated with more efficient capacity of acid- 
base regulation systems (Brauner, 2008; Melzner et al., 2009). Larger sizes induced by acidification scenarios may be related with changes in energy allocation, rather than increased food intake (Hurst et al., 2012), although elevated $\mathrm{pCO}_{2}$ and low $\mathrm{pH}$ may enhance feeding activity through olfactory, gustatory, and consequently appetite stimulations (Munday et al., 2009a) - which were not addressed in this study. Overall, development seems to be differently affected by $p \mathrm{CO}_{2}$ exposures and exposure period. Previously, elsewhere, Silva et al. (2016) reported higher growth in high-acidified conditions - similar to the present work. Nevertheless, extended exposure periods reveal different growth trends, which highlight the importance for additional caution into extrapolating short-term experiments results and the need to address the effects in different life-stages and with longer and more realistic exposures.

Given the tendency for a decrease of lipid peroxidation with increasing acidification values, along with higher lipid content, increase in metabolism and a tendency for smaller body sizes in medium $p \mathrm{CO}_{2}$ treatment after 15 days of exposure, the present results seem to corroborate the assumptions of a change in energy allocation to avoid oxidative stress damage (Fig. 1a, SI and SII). Similar results were observed in Silva et al. (2016), particularly for LPO, which levels decrease with the increase of acidity. Although LPO formation is associated with the increase of oxidative stress (Gutteridge, 1995), even in acidified scenarios with different taxa (Conradi et al., 2016; Freitas et al., 2016a, 2016b), with a 15 days exposure period, the results obtained for Atherina presbyter revealed an opposite pattern with decreasing levels of LPO (Silva et al., 2016). Recent studies have identified a strong effect of elevated $\mathrm{pCO}_{2}$ on the overall fatty acid composition of fish larvae (Frommel et al., 2011; Díaz-Gil et al., 2015), bivalves (e.g., TimminsSchiffmann et al., 2014), and gastropods (e.g., Valles-Regino et al., 2015). Timmins-Schiffmann et al. (2014) reported reduced levels of highly unsaturated fatty acids (components of the cell membrane sensitive to oxidation) in Crassostrea gigas exposed to acidified conditions, suggesting a contribution and possible explanation to lower levels of LPO. Díaz-Gil et al. (2015) identified the reduction in two essential unsaturated fatty acids (EPA, and ARA) associated with larval escape performance on red drum larvae (Sciaenops ocellatus), under increased $p \mathrm{CO}_{2}$ exposures. These authors also suggest that alterations in fatty acid storage and proportion under acidified scenarios may also influence the development performance (Díaz-Gil et al., 2015). Furthermore, in a study with Atlantic cod larvae (Gadus morhua) exposed to acidification scenarios, increasing lipid content, as well as fatty acid variation, namely on essential fatty acids, resulted in organism vulnerability and tissue damage with consequent significant impacts in physiological functions (Frommel et al., 2011). These changes may challenge growth, survivorship and viability of species under global changes and thus, research on this topic following the present study, including a fatty acid profile analysis, should be further addressed.

After 30 days of exposure to the same $p \mathrm{CO}_{2}$ treatments, an abrupt increase in Ec and therefore in cellular oxygen consumption, was observed for organisms in the medium $p \mathrm{CO}_{2}$ treatment (Fig. 1b and SI), while carbohydrates levels remained elevated and lipids decreased, possibly indicating a higher metabolic demand together with an increased energy intake, although feeding rates were not addressed. On the other hand, an abrupt decrease of carbohydrates levels was detected for larvae from high treatment, along with a trend for IDH and LDH increase (despite no alterations in Ec levels). Given the tendency for smaller sizes, organisms from medium treatment might be allocating their energy reserves to maintain physiological and important functions, as well as developing their antioxidant defence strategies (Pimentel et al., 2015), while organisms from high treatment might be allocating energy mostly to growth and other metabolic pathways. Also, a relevant increase in LPO levels was detected for larvae from high treatment at this stage (Fig. 1b and SII), when compared with the same treatment at 15 days of exposure. This may be due to more energy invested for growth and less for oxidative defence strategies in these early stages, which can be corroborated by the lower levels of CAT and SOD on organisms from high treatment at 15 days of exposure (Fig. 1a).

Although the tendency for higher growth in high $p \mathrm{CO}_{2}$ treatment was maintained for 15 and 30 days of exposure, after 45 days a reverse pattern was detected for morphometric endpoints, presenting a decrease in growth for both acidified conditions (Fig. 1c). Higher levels of Ec are associated with less energy available to grow. This pattern can be observed in larvae from high $p \mathrm{CO}_{2}$ treatment at this stage but also in larvae from medium $p \mathrm{CO}_{2}$ treatment at 30 days of exposure (Fig. $1 \mathrm{~b}$ and SI), both with increasing levels of energy consumption and consequent lower growth. Nevertheless, the opposite cannot be excluded in either situation as ontogeny stage affects the development of the antioxidant response system (Pimentel et al., 2015), and thus less energy may be needed to fulfil homeostasis maintenance tasks. However, possible disruptions derived from an extended period of exposure (45 days) to acidification may have also occurred, explaining the continuous higher levels of DNA damage in organisms from medium and high treatment at this stage (Fig. SII). Therefore, it may be hypothesized that a continued exposure to ocean acidification scenarios may induce vulnerable and fragility conditions at the individual level with overall impacts that are still yet to fully unravel.

Another goal of this study was to explore if any potential effect of ocean acidification on sand smelt larvae, exposed for 30 days, was reversible after placing larvae back into control conditions or transferring them between the different treatments, for an extra period of 15 days. Results revealed differences only at the biochemical level. Overall, organisms maintained at the same $p \mathrm{CO}_{2}$ conditions for 30 days presented only few significant differences once moved to a different treatment for an extra 15 days (Fig. 1d). Organisms reared in control, when transferred to acidified conditions, had higher levels of DNA damage, whereas organisms prior exposed to 30 days in acidified conditions did not recover from DNA damage when transferred to less acidified scenarios - within the present timeframe - indicating potential irreversible effects even when those individuals were placed back into control conditions (Fig. 2c). These impacts indicate the potential jeopardy of these scenarios even when site/organism restoring is possible, in endpoints highly related to population and ecosystem success (Lewis and Galloway, 2009). To date, although studies on ocean acidification effects devoted to adaptation and recovery analysis can be characterized as a growing research field (Munday et al., 2010; Chivers et al., 2014; Hamilton, 2014; Hasler et al., 2016), more focus is still required to assess the potential of marine species to adapt to future ocean conditions, because adaptation will/has been undoubtedly occur/occurring, but its analysis is still scarce. Recovering capacity after acidification exposure has been reported in a few fish species, such as the Californian rockfish (Sebastes diploproa), which anxiety levels were reversible (Hamilton, 2014), damselfish (Pomacentrus wardi) that showed restored predator avoidance (Munday et al., 2010; Chivers et al., 2014), and largemouth bass (Micropterus salmoides), which movement behaviour was recovered (Hasler et al., 2016). While the long-term costs of adaptation are still unknown, a wide variation of responses among individuals and treatment groups, as well as its different times to recover to normal values, provide an important target of different adaptation abilities and consequent natural selection (Heuer and Grosell, 2014; Rossi et al., 2015). Thus, the determination of possible trade-offs related with acclimation and adaptation costs, such as altered gene expression and metabolic demand, is crucial to understand if a reduced overall fitness and less ability to cope with this environmental stressor may be related with higher tolerance levels to increased acidity and how this may affect overall dynamics and the ecosystem.

Dramatic changes are expected to occur due to global change impacts. Understanding species sensitivity together with adaptation strategies to ocean acidification is of utmost importance to maximize our knowledge of how ocean chemistry changes may affect species, populations and the entire ecosystems. Therefore, linking integrative knowledge across a diversity of approaches and disciplines must be the 
basis to reach a better understanding of the interaction between ecological impacts and evolutionary changes due to ocean acidification.

\section{Acknowledgment}

This study had the support of Fundação para a Ciência e a Tecnologia (FCT) through the project ACIDLARVAE (PTDC/MAR- EST/ 4627/2012), project PROTEOME (PTDC/AAG-MAA/1302/2014), and the Strategic Project UID/MAR/04292/2013, and grants awarded to Cátia Silva, Ana M. Faria, and Sara C. Novais (SFRH/BD/118195/2016, SFRH/BPD/68673/2010, and SFRH/BPD/94500/2013, respectively). The authors also wish to acknowledge the Integrated Programme of SR \&TD "Smart Valorization of Endogenous Marine Biological Resources Under a Changing Climate" (reference Centro-01-0145-FEDER000018), co-funded by Centro 2020 program, Portugal 2020, European Union, through the European Regional Development Fund.

\section{Appendix A. Supporting information}

Supplementary data associated with this article can be found in the online version at http://dx.doi.org/10.1016/j.ecoenv.2018.02.011.

\section{References}

Abele, D., Puntarulo, S., 2004. Formation of reactive species and induction of antioxidant defence systems in polar and temperate marine invertebrates and fish. Comp. Biochem. Physiol. - Part A: Mol. Integr. Physiol. 138, 405-415.

Aguilera, J., Rautenberger, R., 2010. Oxidative stress tolerance strategies of algae living in the intertidal. In: Abele, D., Zenteno-Savín, T., Vazquez-Medina, J. (Eds.), Oxidative Stress in Aquatic Ecosystems. John Wiley \& Sons, Ltd., Chichester, UK, pp. $58-71$.

Baumann, H., Talmage, S.C., Gobler, C.J., 2012. Reduced early life growth and survival in a fish in direct response to increased carbon dioxide. Nat. Clim. Change 2, 38-41.

Bird, R.P., Draper, A.H., 1984. Comparative studies on different methods of melondyhaldehyde determination. Methods Enzymol. 90, 105-110.

Bisazza, A., Cantalupo, C., Capocchiano, M., Vallortigara, G., 2000. Population lateralisation and social behaviour: a study with 16 species of fish. Laterality 5, 269-284.

Bisazza, A., Rogers, L.J., Vallortigara, G., 1998. The origins of cerebral asymmetry: a review of evidence of behavioural and brain lateralization in fishes, reptiles and amphibians. Neurosci. Biobehav. Rev. 22, 411-426.

Bradford, M., 1976. A rapid and sensitive method for the quantification of microgram quantities of proteins, utilizing the principle of protein dye binding. Anal. Biochem. $72,248-254$.

Brauner, C., 2008. Acid-base balance. In: Finn, R.N., Kapoor, B.G. (Eds.), Fish Larval Physiology. Science Publishers, Enfield, pp. 185-198 (724 pp.). (Analytical Biochemistry, 72, 416-424).

Browman, H.I., 2016. Applying organized scepticism to ocean acidification research. ICES J. Mar. Sci. 73, 529-536.

Cabeçadas, L., Oliveira, A.P., 2005. Impact of a Coccolithus braarudii bloom on the carbonate system of Portuguesecoastal waters. J. Nannoplankton Res. 27 (2), $141-147$.

Castro, J.M., Amorim, M.C.P., Oliveira, A.P., Gonçalves, E.J., Munday, P.L., Simpson, S.D., Faria, A.M., 2017. Painted goby larvae under high-co2 fail to recognize reef sounds. PLOS ONE 12, e0170838.

Chambers, R.C., Candelmo, A.C., Habeck, E.A., Poach, M.E., Wieczorek, D., Cooper, K.R., Greenfiel, C.E., Phelan, B.A., 2014. Effects of elevated $\mathrm{CO}_{2}$ in the early life stages of summer flounder, Paralichthys dentatus, and potential consequences of ocean acidification. Biogeosciences 11, 1613-1626.

Chivers, D.P., McCormick, M.I., Nilsson, G.E., et al., 2014. Impaired learning of predators and lower prey survival under elevated $\mathrm{CO}_{2}$ : a consequence of neurotransmitter interference. Glob. Change Biol. 20, 515-522.

Chung, W.S., Marshall, N.J., Watson, S.A., Munday, P.L., Nilsson, G.E., 2014. Ocean acidification slows retinal function in a damselfish through interference with GABA(A) receptors. J. Exp. Biol. 217, 323-326.

Clairborne, A., 1985. Catalase activity. In: Greenwald, R.A. (Ed.), CRC Handbook of Methods for Oxygen Radical Research. CRC Press, Boca Raton, FL, pp. 283-284.

Conradi, M., Riba, I., Almagro-Pastor, V., DelValls, T.A., 2016. Lethal and sublethal responses in the clam Scrobicularia plana exposed to different $\mathrm{CO}_{2}$-acidic sediments. Environ. Res. 151, 642-652.

De Coen, W.M., Janssen, C.R., 1997. The use of biomarkers in Daphnia magna toxicity testing. IV. Cellular energy allocation: a new methodology to assess the energy budget of toxicant-stressed Daphnia populations. J. Aquat. Ecosyst. Stress Recovery 6, 43-55.

De Coen, W.M., Janssen, C.R., 2003. The missing biomarker link: relationships between effects on the cellular energy allocation biomarker of toxicant-stressed Daphnia magna and corresponding population characteristics. Environ. Toxicol. Chem. 22, $1632-1641$.

Devine, B.M., Munday, P.L., Jones, G.P., 2012. Rising $\mathrm{CO}_{2}$ concentrations affect settlement behaviour of larval damselfishes. Coral Reefs 31, 229-238.

Diamantino, T.C., Almeida, E., Soares, A.M.V.M., Guillermino, L., 2001. Lactate dehydrogenase activity as an effect criterion in toxicity tests with Daphnia magna Strauss. Chemosphere 45, 553-560.

Díaz-Gil, C., Catalán, I.A., Palmer, M., Faulk, C.K., Fuiman, L.A., 2015. Ocean acidification increases fatty acids levels of larval fish. Biol. Lett. 11, 20150331.

Dixson, D.L., Munday, P.L., Jones, G.P., 2010. Ocean acidification disrupts the innate ability of fish to detect predator olfactory cues. Ecol. Lett. 13, 68-75.

Domenici, P., Allan, B.J.M., McCormick, M.I., Munday, P.L., 2012. Elevated carbon dioxide affects behavioural lateralization in a coral reef fish. Biol. Lett. 8, 78-81.

Ellis, G., Goldberg, D.M., 1971. An improved manual and semi-automatic assay for NADP dependent isocitrate dehydrogenase activity, with a description of some kinetic properties of human liver and serum enzyme. Clin. Biochem. 2, 175-185.

Freitas, R., Pires, A., Moreira, A., Wrona, F.J., Figueira, E., Soares, A.M.V.M., 2016a. Biochemical alterations induced in Hediste diversicolor under seawater acidification conditions. Mar. Environ. Res. 117, 75-84.

Freitas, R., Pires, A., Velez, C., Almeida, A., Moreira, A., Wrona, F.J., Soares, A.M.V.M., Figueira, E., 2016b. Effects of seawater acidification on Diopatra neapolitand (Polychaete, Onuphidae): biochemical and regenerative capacity responses. Ecol. Indic. 60, 152-161.

Frommel, A.Y., Maneja, R., Lowe, D., et al., 2011. Severe tissue damage in Atlantic cod larvae under increasing ocean acidification. Nat. Clim. Change 2, 42-46.

Gnaiger, E., 1983. Calculation of energetic and biochemical equivalents of respiratory oxygen consumption. In: Gnaiger, E., Forstner, H. (Eds.), Polarographic Oxygen Sensors. Aquatic and Physiological Applications. Springer, Berlin, Heidelberg, New York, pp. 337-345.

Gutteridge, J.M.C., 1995. Lipid peroxidation and antioxidants as biomarkers of tissue damage. Clin. Chem. 41, 1819-1828.

Hamilton, T.J., Holcombe, A., Tresguerres, M., 2014. $\mathrm{CO}_{2}$-induced ocean acidification increases anxiety in Rockfish via alteration of GABAA receptor functioning. Proc. R. Soc. B 281, 20132509.

Hamilton, S.L., Logan, C.A., Fennie, H.W., et al., 2017. Species-specific responses of juvenile rockfish to elevated $\mathrm{pCO}_{2}$ : from behavior to genomics. PLoS ONE 12, e0169670.

Hasler, C.T., Midway, S.R., Jeffrey, J.D., Tix, J.A., Sullivan, C., Suski, C.D., 2016. Exposure to elevated $p \mathrm{CO}_{2}$ alters post-treatment diel movement patterns of largemouth bass over short time scales. Freshw. Biol. 61, 1590-1600.

Heuer, R., Grosell, M., 2014. Physiological impacts of elevated carbon dioxide and ocean acidification on fish. Am. J. Physiol.: Regul. Integr. Comp. Physiol. 307, R1061-R1084.

Hoegh-Guldberg, O., Mumby, P.J., Hooten, A.J., et al., 2007. Coral reefs under rapid climate change and ocean acidification. Science 318, 1737-1742.

Huggett, R.J., Kimerle, R.A., Mehrle, P.M., Bergman, H.L., 1992. Biomarkers: biochemical, physiological and histological markers of anthropogenic stress. Lewis, Boca Raton, Fla, USA, pp. 346.

Hurst, T.P., Fernandez, E.R., Mathis, J.T., Miller, J.A., Stinson, C.M., Ahgeak, E.F., 2012. Resiliency of juvenile walleye pollock to projected levels of ocean acidification. Aquat. Biol. 17, 247-259.

IPCC, 2014. In: Edenhofer, O., Pichs-Madruga, R., Sokona, Y., Farahani, E., Kadner, S., Seyboth, K., Adler, A., Baum, I., Brunner, S., Eickemeier, P., Kriemann, B., Savolainen, J., Schlömer, S., von Stechow, C., Zwickel, T., Minx, J.C. (Eds.), Climate Change 2014: Mitigation of Climate Change. Contribution of Working Group III to the Fifth Assessment Report of the Intergovernmental Panel on Climate Change. Cambridge University Press, Cambridge, United Kingdom and New York, NY, USA.

Jones, J.P., McCormick, M.I., 2002. Numerical and energetic processes in the ecology of coral reef fishes. In: Sale, P.F. (Ed.), Coral Reef Fishes: Dynamics and Diversity in a Complex Ecosystem. Academic Press, San Diego, pp. 221-238.

Jutfelt, F., Bresolin de Souza, K., Vuylsteke, A., Sturve, J., 2013. Behavioural disturbances in a temperate fish exposed to sustained high- $\mathrm{CO}_{2}$ levels. PLoS ONE 8, e65825.

Kamyab, E., Kühnhold, H., Novais, S.C., Alves, L.M.F., Indriana, L., Kunzmann, A., Slater, M., Lemos, M.F.L., 2017. Effects of thermal stress on the immune and oxidative stress responses of juvenile sea cucumber Holothuria scabra. J. Comp. Physiol. B 187, 51-61.

Kerr, R.A., 2010. Ocean acidification unprecedented, unsettling. Science 328, 1500-1501.

King, F.D., Packard, T.T., 1975. Respiration and the activity of the respiratory electron transport system in marine zooplankton. Limnol. Oceanogr. 20, 849-854.

Lafontaine, Y., Gagne, F., Blaise, F., Costan, G., Gagnon, P., Chan, H., 2000. Biomarkers in zebra mussels (Dreissena polymorpha) for the assessment and monitoring of water quality of the St Lawrence River (Canada). Aquat. Toxicol. 50, 51-71.

Legendre, L., Legendre, P., 1979. Écologie numérique. Tome 1: Le traitement multiple des données écologiques. Collection d'Écologie no 12 Xiv. Masson, Paris et les Presses de l’Université du Québec, pp. 197.

Lemos, M.F.L., Soares, M.V.M., Correia, A.C., Esteves, C., 2010. Proteins in ecotoxicology - how, why and why not? Proteomics 10, 873-887.

Le Quesne, W.J.F., Pinnegar, J.K., 2012. The potential impacts of ocean acidification: scaling from physiology to fisheries. Fish. Fish. 13, 333-344.

Lesser, M.P., 2011. Oxidative stress in tropical marine ecosystems. In: Abele, D., ZentenoSavín, T., Vazquez-Medina, J. (Eds.), Oxidative Stress in Aquatic Ecosystems. John Wiley \& Sons, Ltd., Chichester, UK, pp. 7-19.

Lewis, C., Galloway, T., 2009. Reproductive consequences of paternal genotoxin exposure in marine invertebrates. Environ. Sci. Technolology 43 (3), 928-933.

Lima, I., Moreira, S.M., Osten, J.R., Soares, A.M.V.M., Guilhermino, L., 2007. Biochemical responses of the marine mussel Mytilus galloprovincialis to petrochemical environmental contamination along the northwestern coast of Portugal. Chemosphere 66, 1230-1242.

Lopes, A.F., Morais, P., Pimentel, M., Rosa, R., Munday, P.L., Gonçalves, E.J., Faria, A.M., 2016. Behavioural lateralization and shoaling cohesion of fish larvae altered under 
ocean acidification. Mar. Biol. 163, 243.

McCord, J.M., Fridovich, I., 1969. Superoxide dismutase. An enzymic function for erythrocuprein (hemocuprein). J. Biol. Chem. 244, 6049-6055.

Melzner, F., Gutowska, M.A., Langenbuch, M., Dupont, S., Lucassen, M., Thorndyke, M.C., Bleich, M., Pörtner, O., 2009. Physiological basis for high $\mathrm{CO}_{2}$ tolerance in marine ectothermic animals: pre-adaptation through lifestyle and ontogeny? Biogeosciences 6, 2313-2331.

Millero, F.J., Graham, T.B., Huang, F., Bustos-Serrano, H., Pierrot, D., 2006. Dissociation constants of carbonic acid in seawater as a function of salinity and temperature. Mar. Chem. 100, 80-94.

Munday, P.L., Dixson, D.L., Donelson, J.M., Jones, G.P., Pratchett, M.S., Devitsina, G.V., Doving, K.B., 2009a. Ocean acidification impairs olfactory discrimination and homing ability of a marine fish. Proc. Natl. Acad. Sci. USA 106, 1848-1852.

Munday, P.L., Donelson, J.M., Dixson, D.L., Endo, G.G.K., 2009b. Effects of ocean acidification on the early life history of a tropical marine fish. Proc. R. Soc. B 276, 3275-3283.

Munday, P.L., Dixson, D.L., McCormick, M.I., Meekan, M., Ferrari, M.C.O., Chivers, D.P., 2010. Replenishment of fish populations is threatened by ocean acidification. Proc. Natl. Acad. Sci. USA 107, 12930-12934.

Munday, P.L., Gagliano, M., Donelson, J.M., Dixson, D.L., Thorrold, S.R., 2011. Ocean acidification does not affect the early life history development of a tropical marine fish. Mar. Ecol. Progress. Ser. 423, 211-221.

Nagelkerken, I., Munday, P.L., 2016. Animal behaviour shapes the ecological effects of ocean acidification and warming: moving from individual to community-level responses. Glob. Change Biol. 22, 974-989.

Nagelkerken, I., Connell, S.D., 2015. Global alteration of ocean ecosystem functioning due to increasing human $\mathrm{CO}_{2}$ emissions. Proc. Natl. Acad. Sci., USA 112, 13272-13277.

Ohkawa, H., Ohishi, N., Yagi, K., 1979. Assay for lipid peroxides in animal tissues by thiobarbituric acid reaction. Anal. Biochem. 95, 351-358.

Olive, P., 1988. DNA precipitation assay - a rapid and simple method for detecting DNA damage in mammalian cells. Environ. Mol. Mutagen. 11, 487-495.

Orr, J.C., Fabry, V.J., Aumont, O., et al., 2005. Anthropogenic ocean acidification over the twenty-first century and its impact on calcifying organisms. Nature 437, 681-686.

Pan, T.C.F., Applebaum, S.L., Manahan, D.T., 2015. Experimental ocean acidification alters the allocation of metabolic energy. Proc. Natl. Acad. Sci. 112, 4696-4701.

Perry, D.M., Redman, D.H., Widman, J.C., Meseck, S., King, A., Pereira, J.J., 2015. Effect of ocean acidification on growth and otolith condition of juvenile scup, Stenotomus chrysops. Ecol. Evol. 5, 4187-4196.

Pierrot, D., Lewis, E., Wallace, D.W.R., 2006. MS Excel Program Developed for $\mathrm{CO}_{2}$ System Calculations., ORNL/CDIAC-105. Carbon Dioxide Information Analysis
Center, Oak Ridge National Laboratory, U.S. Department of Energy, Oak Ridge, Tennessee.

Pimentel, M.S., Faleiro, F., Diniz, M., Machado, J., Pousão-Ferreira, P., Peck, M.A., Pörtner, H.O., Rosa, R., 2015. Oxidative stress and digestive enzyme activity of flatfish larvae in a changing ocean. PLoS One 10 (7), e0134082.

Rato, L.D., Novais, S.C., Lemos, M.F.L., Alves, L.M.F., Leandro, S.M., 2017. Homarus gammarus (Crustacea: Decapoda) larvae under an ocean acidification scenario: responses across different levels of biological organization. Comp. Biochem. Physiol. Part C: Toxicol. Pharmacol. 203, 29-38.

Rossi, T., Nagelkerken, I., Simpson, S.D., et al., 2015. Ocean acidification boosts larval fish development but reduces the window of opportunity for successful settlement. Proc. R. Soc. B 282, 20151954.

Schunter, C., Welch, M.J., Ryu, T., Zhang, H., Berumen, M.L., Nilsson, G.E., Munday, P.L., Ravasi, T., 2016. Molecular signatures of transgenerational response to ocean acidification in a species of reef fish. Nat. Clim. Change 6, 1014-1018.

Silva, C.S.E., Novais, S.C., Lemos, M.F.L., Mendes, S., Oliveira, A.P., Gonçalves, E.J., Faria, A.M., 2016. Effects of ocean acidification on the swimming ability, development and biochemical responses of sand smelt larvae. Sci. Total Environ. 563-564, 89-98.

Stiasny, M.H., Mittermayer, F.H., Sswat, M., et al., 2016. Ocean acidification effects on Atlantic cod larval survival and recruitment to the fished population. PLoS ONE 11, e0155448.

Ter Braak, C.J.F., 1986. Canonical correspondence analysis: a new eigenvector technique for multivariate direct gradient analysis. Ecology 67, 1167-1179.

Ter Braak, C.J.F., Smilauer, P., 1998. CANOCO Reference Manual and User's Guide to Canoco for windows - Software for Canonical Community Ordination (Version 4). Microcomputer Power, Ithaca, NY.

Timmins-Schiffmann, E., Coffey, W.D., Hua, W., Nunn, B.L., Dickinson, G.H., Roberts, S.B., 2014. Shotgun proteomics reveals physiological response to ocean acidification in Crassostrea gigas. BMC Genom. 15, 1-59.

Tonn, N., Novais, S.C., Silva, C.S.E., Morais, H.A., Correia, J.P.S., Lemos, M.F.L., 2016. Stress responses of the sea cucumber Holothuria forskali during aquaculture handling and transportation. Mar. Biol. Res. 12, 948-957.

Valles-Regino, R., Tate, R., Kelaher, B., Savins, D., Dowell, A., Benkendorff, K., 2015 Ocean warming and $\mathrm{CO}_{2}$-induced acidification impact the lipid content of a marine predatory gastropod. Marine Drugs 13, 6019-6037.

Vassault, A., 1983. Methods of Enzymatic Analysis. Academic Press, NY, pp. 118-126.

Weiss, R.F., 1974. Carbon dioxide in water and seawater: the solubility of a non-ideal gas. Mar. Chem. 2, 203-215.

Zar, J.H., 2010. Biostatistical Analysis, 5th ed. Pearson Prentice-Hall, Upper Saddle River, New Jersey, USA. 